\title{
The use of chloroplast genome sequences to solve phylogenetic incongruences in Polystachya Hook (Orchidaceae Juss)
}

\author{
Narjara Lopes de Abreu ${ }^{\text {Corresp., }}{ }^{1,2}$ ， Ruy José Válka Alves ${ }^{2}$ ， Sérgio Ricardo Sodré Cardoso \\ Filipe Sousa ${ }^{1,4}$, Climbiê Ferreira Hall ${ }^{5}$, Bernard E Pfeil ${ }^{1}$, Alexandre Antonelli ${ }^{1,6,7,8}$ \\ 1 Department of Biological and Environmental Sciences, University of Gothenburg, Göteborg, Sweden \\ 3 Instituto de Pesquisas, Jardim Botânico do Rio de Janeiro, Diretoria de Pesquisa Científica, Rio de Janeiro, Brasil \\ 4 Centro de Ciências do Mar, Universidade do Algarve, Faro, Portugal \\ 5 Campus Três Lagoas, Universidade Federal de Mato Grosso do Sul, Três Lagoas, Mato Grosso do Sul, Brasil \\ 6 Gothenburg Botanical Garden, Göteborg, Sweden \\ 7 Gothenburg Global Biodiversity Centre, Göteborg, Sweden \\ 8 Department of Organismic and Evolutionary Biology, Harvard University, Cambridge, Massachusetts, United States \\ Corresponding Author: Narjara Lopes de Abreu \\ Email address: narjara.lopes@gmail.com
} Yann JK Bertrand ${ }^{1}$

Background. Current evidence suggests that for more robust estimates of species tree and divergence times, several unlinked genes are required. However, most phylogenetic trees for non-model organisms are based on single sequences or just a few regions, using traditional sequencing methods. Techniques for massive parallel sequencing or Next Generation Sequencing are an alternative to traditional methods that allow access to hundreds of DNA regions. Here we use this approach to resolve the phylogenetic incongruence found in Polystachya Hook. (Orchidaceae), a genus that stands out due to several interesting aspects, including cytological (polyploid and diploid species), evolutionary (reticulate evolution) and biogeographical (species widely distributed in the tropics and high endemism in Brazil). The genus has a notoriously complicated taxonomy, with several sections that are widely used but probably not monophyletic. Methods. We generated the complete plastid genome of 40 individuals from one clade within the genus. The method consisted in construction of genomic libraries, hybridisation to RNA probes designed from available sequences of a related species, and subsequent sequencing of the product. We also tested how well a smaller sample of the plastid genome would perform in phylogenetic inference in two ways: by duplicating a fast region and analysing multiple copies of this dataset, and by sampling without replacement from all non-coding regions in our alignment. We further examined the phylogenetic implications of non-coding sequences that appear to have undergone hairpin inversions (reverse complemented sequences associated with small loops). 
Results. We retrieved 131,214 bp, including coding and non-coding regions of the plastid genome. The phylogeny was able to fully resolve the relationships among all species in the targeted clade with high support values. The first divergent species are represented by African accessions and the most recent ones are among Neotropical species.

Discussion. Our results indicate that using the entire plastid genome is a better option than screening highly variable markers, especially when the expected tree is likely to contain many short branches. The phylogeny inferred is consistent with the proposed origin of the genus, showing a probable origin in Africa, with later dispersal into the Neotropics, as evidenced by a clade containing all Neotropical individuals. The multiple positions of Polystachya concreta (Jacq.) Garay \& Sweet in the phylogeny are explained by allotetraploidy. Polystachya estrellensis Rchb.f. can be considered a genetically distinct species from $P$. concreta and $P$. foliosa (Lindl.) Rchb.f., but the delimitation of $P$. concreta remains uncertain. Our study shows that next generation sequencing provides a powerful tool for inferring relationships at low taxonomic levels, even in taxonomically challenging groups with short branches and intricate morphology. 
1 Manuscript submission to PeerJ.

2

3 This paper is part of the Collection: "Endless forms: Advances in evolutionary analyses of 4 biodiversity"

5

\section{THE USE OF CHLOROPLAST GENOME SEQUENCES TO SOLVE PHYLOGENETIC INCONGRUENCES IN POLYSTACHYA HOOK. (ORCHIDACEAE JUSS.).}

Narjara Lopes de Abreu ${ }^{1,2 *}$, Ruy José Válka Alves ${ }^{1}$, Sérgio Ricardo Sodré Cardoso ${ }^{3}$, Yann J.K. Bertrand $^{2}$, Filipe Sousa ${ }^{2,4}$, Climbiê Ferreira Hall ${ }^{5}$, Bernard E. Pfeil ${ }^{2}$, \& Alexandre Antonelli2,6,7,8§

${ }^{1}$ Museu Nacional, Universidade Federal do Rio de Janeiro, São Cristóvão, Rio de Janeiro, Brasil ${ }^{2}$ Department of Biological and Environmental Sciences, University of Gothenburg, Box 463, 405 30 Göteborg, Sweden.

6 Instituto de Pesquisas, Jardim Botânico do Rio de Janeiro, Diretoria de Pesquisa Científica, Rio 7 de Janeiro, Brasil.

${ }^{4}$ CCMAR (Centro de Ciências do Mar da Universidade do Algarve), Edifício 7, Gambelas 8005139, Faro, Portugal.

${ }^{5}$ Campus Três Lagoas, Universidade Federal de Mato Grosso do Sul, Três Lagoas, Mato Grosso do Sul, Brasil.

${ }^{6}$ Gothenburg Botanical Garden, Carl Skottsbergs gata 22A, SE-41319 Göteborg, Sweden.

3 7Gothenburg Global Biodiversity Centre, Box 461, SE-405 30 Göteborg, Sweden.

$4{ }^{8}$ Department of Organismic and Evolutionary Biology, Harvard University, 26 Oxford St., Cambridge, MA 02138 USA

* Corresponding Author:

Narjara Abreu ${ }^{1}$. Email address: narjara.lopes@gmail.com

9 Bernard Pfeil2 ${ }^{2}$.Email address: bernard.pfeil@gu.se 
$\S$ Both are senior authors in this paper.

\section{ABSTRACT}

32 Background. Current evidence suggests that for more robust estimates of species tree and divergence times, several unlinked genes are required. However, most phylogenetic trees for non-model organisms are based on single sequences or just a few regions, using traditional sequencing methods. Techniques for massive parallel sequencing or Next Generation Sequencing are an alternative to traditional methods that allow access to hundreds of DNA regions. Here we use this approach to resolve the phylogenetic incongruence found in Polystachya Hook. (Orchidaceae), a genus that stands out due to several interesting aspects, including cytological (polyploid and diploid species), evolutionary (reticulate evolution) and biogeographical (species widely distributed in the tropics and high endemism in Brazil). The genus has a notoriously complicated taxonomy, with several sections that are widely used but probably not monophyletic.

Methods. We generated the complete plastid genome of 40 individuals from one clade within the genus. The method consisted in construction of genomic libraries, hybridisation to RNA probes designed from available sequences of a related species, and subsequent sequencing of the product. We also tested how well a smaller sample of the plastid genome would perform in phylogenetic inference in two ways: by duplicating a fast region and analysing multiple copies of this dataset, and by sampling without replacement from all non-coding regions in our alignment. We further examined the phylogenetic implications of non-coding sequences that appear to have undergone hairpin inversions (reverse complemented sequences associated with small loops).

Results. We retrieved 131,214 bp, including coding and non-coding regions of the plastid genome. The phylogeny was able to fully resolve the relationships among all species in the targeted clade with high support values. The first divergent species are represented by African accessions and the most recent ones are among Neotropical species.

Discussion. Our results indicate that using the entire plastid genome is a better option than screening highly variable markers, especially when the expected tree is likely to contain many 
60 short branches. The phylogeny inferred is consistent with the proposed origin of the genus,

61 showing a probable origin in Africa, with later dispersal into the Neotropics, as evidenced by a

62 clade containing all Neotropical individuals. The multiple positions of Polystachya concreta

63 (Jacq.) Garay \& Sweet in the phylogeny are explained by allotetraploidy. Polystachya

64 estrellensis Rchb.f. can be considered a genetically distinct species from $P$. concreta and $P$.

65 foliosa (Lindl.) Rchb.f., but the delimitation of $P$. concreta remains uncertain. Our study shows

66 that next generation sequencing provides a powerful tool for inferring relationships at low

67 taxonomic levels, even in taxonomically challenging groups with short branches and intricate

68 morphology.

69

\section{INTRODUCTION}

Orchidaceae is considered the largest family of Flowering Plants, with over 25,000 species (Dressler, 1990; Christenhusz \& Byng, 2016). The family probably dates back to the Late Cretaceous, as indicated by fossil-calibrated molecular phylogenies (Gustafsson, Verola \& Antonelli, 2010; Ramirez et al., 2007, 2011). Polystachya Hook. is an orchid genus containing 240 species, with most species found in Africa (Dressler, 1993). Thirteen species are reported from the Neotropical region (Mytnik-Ejsmont, 2011), but this number may increase when considering the endemic species from Brazil that were not accounted for in Mytnik-Ejsmont (2011) or were considered synonymous (Barros et al., 2010).

Recent studies have shown a number of peculiar cytological, evolutionary and biogeographic aspects of Polystachya. The genus has diploid and polyploid species, the latter recently formed in the Neotropics and Madagascar (Rupp et al., 2010; Russell et al., 2010b). Unlike most genera of Orchidaceae, Polystachya has a wide geographical distribution range

84 (Pridgeon et al., 2005; Fig. 1), having species that are Pantropical or have a transatlantic distribution. On the other hand, the Neotropics presents a high level of endemism. Brazil, as an example, has 12 species of which 10 are endemic (Barros et al., 2010). In addition, there is et al., 2010a). 
The monophyly of the genus has been reported in the latest studies (Russell et al., 2010b;

90

Mytnik-Ejsmont, 2011), which contrasts starkly with the low level of monophyly observed in the taxonomic sections described within the genus. Those 15 sections (Kraenzlin, 1926;

Summerhayes, 1942, 1947 apud Russell et al., 2011b; Brenan, 1954; Cribb, 1978) are based on morphological characters and have been useful for field identification and inventories, but do not find support as natural groupings in the molecular studies currently available (Russell et al., 2010b; Mytnik-Ejsmont, 2011). According to those molecular studies, all sections are polyphyletic or paraphyletic, except sect. Isochiloides (Russell et al., 2010b).

Section Polystachya has been described as comprising 32 species worldwide and is the only section with species of pantropical distribution (Mytnik-Ejsmont, 2011). However, according to molecular analyses, some species of this section appear to be more related to species of other sections (Russell et al., 2010b; Mytnik-Ejsmont, 2011). These studies highlight the need for new infrageneric divisions based on robust molecular evidence. Russell et al. (2010b), using chloroplast markers, defined five different clades that could be used as the basis for a revised classification of new sections within the genus. Clade III (sensu Russel et al., 2010b) includes species from five different sections (sects. Polystachya, Eurychilae, Caulescentes, Superpositae, Polychaete) and is divided into distinct subclades of morphologically diverse plants. These species are Pantropical (such as P concreta), Neotropical (such as P.foliosa), Malagasy endemics (such as P. henrici) or African (such as P. odorata). The relationships among Clade III species remain unresolved because specimens of $P$. concreta, $P$. foliosa, $P$. henrici, and $P$. modesta form a large polytomy, due to low levels of divergence between sequences. In addition, several distinct subclades are unresolved at the base. The molecular phylogenetic studies produced so far have included about $35 \%$ of the recognized species within the genus, and used only a small number of nuclear (PgiC between exons 11 and 15, PhyC exon 1, Rpb2 intron 23 and ITS in Russell et al., 2010a; only ITS in Mytnik-Ejsmont, 2011) and chloroplast markers (rps 16 intron, rps 16 exon 2, rps 16-trnK spacer, $\operatorname{trn} K$ intron excluding matK, matK and psbD-trnT spacer in Russell et al., 2010b; rps16-trnK, rps 16 and rpl32-trnL in Mytnik-Ejsmont, 2011).

1 New methods of DNA sequencing as well as the development of more powerful algorithms are propelling the replacement of trees generated from one or a few genes to those constructed from hundreds of them (Edwards, 2009). The improvement of massively parallel 
120 sequencing techniques - or Next Generation Sequencing (NGS) - has increased the amount of

121 data available for biological research, whether the fully annotated reference genomes of species

122 under study have been sequenced or not (Bräutigam \& Gowik, 2010). However, despite its

123 obvious potential, NGS technology is underused in most studies of plant systematics (Cronn et

124 al., 2012; Carstens et al., 2013; Eaton \& Ree, 2013), probably as a result of a prevailing focus on

125 non-model organisms (which require de novo genomic sequencing and its inherent challenges),

126 the need to sample many individuals per species and the absence of well-established protocols

127 (McCormack, 2013). One method that increases the efficiency of NGS for non-model species

128 compared to other genomic partitioning strategies is sequence capture (or hybridisation-based

129 enrichment), which is based on the prior selection of loci of interest (Lemmon \& Lemmon,

130 2013). The main benefit of this technique is that the number of specific sequences obtained can

131 be very high, which makes it an advantageous method compared to PCR-based approaches if the

132 objective is to sequence several individuals and multiple loci. Furthermore, sequence capture

133 when combined with NGS platforms, such as Illumina, also reduces the costs of the process

134 (Lemmon, Emme \& Lemmon, 2012). Sequence capture methods have successfully been used in

135 other plant genera to generate large amounts of useful data for phylogenetic inference (Kamneva

136 et al., 2017; Sousa et al., 2014; Stephens et al., 2015; Weitemier et al., 2014)

137 The necessity of a molecular phylogenetic framework for (and a morphological

138 taxonomic revision of) Polystachya is clear. It requires a well-resolved phylogenetic hypothesis

139 in order to clarify the relationships between species and also to redefine new infrageneric

140 sections. In this paper, we explore the use of nearly complete plastid genomes (note that we use

141 chloroplast and plastid interchangeably when referring to these genomes), obtained by sequence

142 capture and massively parallel sequencing, to solve the phylogenetic inconsistencies found

143 within Clade III of Polystachya (sensu Russell et al., 2010b). We also explore whether

144 sequencing the entire chloroplast genome using NGS was worthwhile, compared to PCR and

145 Sanger sequencing of a few fast-evolving loci. We hope that the results generated here can be

146 extended to the rest of the genus and thus result in new interpretations of the evolutionary and

147 biogeographic history of the group.

148 
151 We sampled 19 species and 48 individuals (Table 1, Fig. 1), of which 15 were collected

152 in different locations in continental Brazil and three were collected on Trindade Island in the

153 South Atlantic. The DNA of the 15 Brazilian samples was extracted from $10 \mathrm{mg}$ of tissue dried

154 with silica gel and using the DNeasy Plant Mini Kit (Qiagen). DNA samples for the remaining

15533 individuals were provided by the University of Vienna and the DNA bank of the Royal

156 Botanic Gardens, Kew. To this sample of individuals, selected because they cluster in Clade III

157 (as defined in Russell et al., 2010b), we added Polystachya tessellata Lindl., supposedly

158 synonymous of $P$. concreta. We also included multiple samples of $P$. concreta, because previous

159 studies have reported a lack of monophyly for this species and several synonymous species.

160 Permits to collect were provided by the Ministério do Meio Ambiente (MMA), Instituto Chico

161 Mendes de Conservação da Biodiversidade (ICMBio) and Sistema de Autorização e Informação

162 em Biodiversidade (SISBIO), with registration number 29478-1.

163 Polystachya bicolor Rolfe and P. melanantha Schltr. were chosen as possible more

164 distant relatives of the species in focus, in order to provide additional context for the

165 phylogenetic inference. All studies conducted to date resolve P. melanantha as an outgroup with

166 respect to the Clade III species. Polystachya bicolor has already been treated as a synonym of $P$.

167 rosea (Mytnik-Ejsmont, 2011), with an uncertain position in the phylogenetic trees generated

168 thus far, being sometimes closely related to P. concreta and other associated species (Mytnik-

169 Ejsmont, 2011) and sometimes closely related to species from other clades (Russell et al., 2010b;

170 Mytnik-Ejsmont, 2011).

171

172 Probe Design for DNA Capture

173 We used complete chloroplast genome of Phalaenopsis aphrodite subsp. formosana

174 (NC_007499.1) (Chang et al., 2006) as the reference for the design of capture probes, because

175 there is no completely sequenced chloroplast genome of a Polystachya. According to molecular

176 analyses, Polystachya and Phalaenopsis belong to different sub-tribes but are closely related

177 within the Vandeae tribe (Van Den Berg et al., 2005; Górniak, Paun \& Chase, 2010;

178 Freudenstein \& Chase, 2015). The use of a quite distantly related species is made possible by the 
179 DNA capture kit (MyBaits), which is able to support differences larger than 5\% between probe 180 sequences and target sequences (e.g., Li et al., 2013). The complete sequence of the chloroplast genome of Phalaenopsis aphrodite subsp. formosana was divided into blocks of $360 \mathrm{bp}$. Every

182 second block was used as the template for probe design; the probes consisting of $120 \mathrm{bp}$

183 sequences, three to each block without overlap. Given the genomic DNA fragment sizes of

184 between 300-400 bp (below) and that fragments can contain complementary sequence anywhere

185 on their length to attach to a probe, fragments can contain up to 200-300 bp of genomic sequence

186 into the flanking regions beyond the probes, or cover the probes with little extent into the

187 flanking sequence, or somewhere in between. In this way, captured sequences produce a series of

188 tiled overlapping sequence for high quality genomic assembly. Additionally, fragments with a

189 base repeated more than seven times in a row were avoided to reduce the capture of repetitive

190 sequences present in many places in the genome. Finally, the reference sequences in blocks used

191 for probe design totalled 63,720 bp and were brought together into a single FASTA file and sent

192 to MYcroarray (Ann Arbor, Michigan, USA) to produce the probes.

193 Data Generation

\section{Sonication and genomic library preparation}

Extracted DNA was randomly fragmented by sonication using a Covaris S220 instrument

196 (Covaris, Woburn, Massachusetts, USA), in order to evenly cover the full genome. Adapters

197 were incorporated into the fragmented DNA using NEXTflexTM DNA Sequencing Kit and

198 NEXflexTM Barcodes kit (BIOO Scientific, Austin, Texas, USA). Uniquely indexed adapters

199 were used for each sample. We selected fragments between 300 and 400 bp using

200 AgencourtAMPure XP magnetic beads kit (Beckman Coulter). The genomic library was

201 amplified following the program: $98^{\circ} \mathrm{C}$ for 2 minutes; 14 cycles $\left(98^{\circ} \mathrm{C}\right.$ for 30 seconds; $65^{\circ} \mathrm{C}$ for

20230 seconds; $72^{\circ} \mathrm{C}$ for 60 seconds); $72^{\circ} \mathrm{C}$ for 4 minutes. The products were purified using a

203 QIAquick PCR Purification Kit (Qiagen). The genomic DNA concentrations before and after

204 sonication and the amplification of the library were measured in a NanoDrop 2000c instrument

205 (Thermo Fisher Scientific, Waltham, MA, USA) (Table 1) to ensure that the final concentration 206 exceeded 400ng/ $\mu \mathrm{L}$. 


\section{Enrichment and sequencing}

208 Before the enrichment, equimolar amounts $(400 \mathrm{ng} / \mu \mathrm{L})$ of each amplified library were pooled into six reactions, each one containing eight indexed samples. The enrichment method

210 involves the selection of genomic regions and capture of DNA samples before sequencing

211 (Mamanova et al., 2010). The enrichment was performed with MYBaits target enrichment 212 system (MYcroarray, Ann Arbor, Michigan), following the manufacturer's instructions. The 213 probes were recovered using Dynabeads ${ }^{\circledR}$ MyOneTM Streptavidin C1 (Invitrogen Dynal AS, 214 Oslo, Norway).

215 To increase DNA concentration, 14 cycles of PCR were performed for each hybridisation 216 reaction using Herculase II Fusion DNA Polymerase (Agilent, Waldbronn, Germany) and the 217 following program: $98^{\circ} \mathrm{C}$ for 30 seconds; 14 cycles $\left(98^{\circ} \mathrm{C}\right.$ for 20 seconds; $60^{\circ} \mathrm{C}$ for 30 seconds; $21872^{\circ} \mathrm{C}$ for 60 seconds), $72^{\circ} \mathrm{C}$ for 5 minutes. Sequencing was performed on the Illumina MiSeq 219 platform (San Diego, California, USA) by the Genomics Core Facility (University of 220 Gothenburg, Sweden).

\section{Sequence editing}

222

Illumina reads were processed using the program CLC assembly cell (CLC Bio, Aarhus, Denmark). Firstly, the Illumina adapter sequences were removed and low-quality reads were excluded. Reads were then mapped against the reference sequence used for probe design (Phalaenopsis aphrodite). Consensus sequences generated for each sample were converted into FASTA format using the SAMTools software (Li et al. 2009) using the mpileup tool with reference sequence option, allowing for the inclusion of indels in the consensus sequences. These sequences were used as a new individual reference sequences for each sample in a second round of mapping. Final consensus sequences were generated using mpileup, without the reference sequence option, to avoid erroneous base calling in low read-depth portions of the read alignment. Sequence alignment was performed using the auto strategy in MAFFT - Multiple

232 Sequence Alignment Software Version 7 (Katoh \& Standley, 2013) and later manually refined 233 using Geneious Pro (Biomatters). In the last step we aligned the sequenced samples with the 234 Phalaenopsis aphrodite subsp. formosana (NC_007499.1) chloroplast genome to obtain the 235 sequenced region annotation." 
238

239

240

241

242

243

244

245

246

247

248

249

250

251

252

253

254

255

256

257

258

259

260

261

262

263

264

265

\section{Alignment and Phylogenetic Analysis}

\section{Hairpin inversions}

Micro-structural features of chloroplast non-coding sequences can have a profound influence on the multiple sequence alignment, and hence also the phylogeny. Hairpins (short stem-loop structures in single stranded DNA or RNA), for example, can create sites that allow small inversions to occur at a high enough frequency that homoplasious inversions can be observed among sequences from closely related species (Kelchner \& Wendel, 1996). Sometimes the inverted sequence is not so short and can disrupt phylogenetic analysis, leading to strongly supported but spurious groupings (Joly et al., 2010). Non-coding sequences, such as group II chloroplast introns, contain many such stem-loop structures (Kelchner, 2002).

We examined the non-coding sequences in our alignment for inverted (reverse complemented) sequences and tested for their effect on the phylogenetic inference. This was done by excluding all but one character of the inversion (to down-weight the inversion to a single event) and rerunning the analysis. The selected character to represent the inversion was arbitrarily chosen. This was done to avoid recoding the inversions as indel characters and creating a new, small partition (with only eight characters) that would have required many additional parameters, in comparison to our approach.

\section{Site exclusions}

The alignment process can sometimes be confronted with small regions that are difficult to align, probably most often due to overlapping indel events. We identified several such regions and excluded them using the nexus block commands from the Bayesian analysis. Poor alignment excluded sites: 54459-54465, 55220-55224, 55484-55489, 67162-67167, 67426-67431, 6818668192, 118838-118843, 119266-119364, 119493-119726, 120012-120019, 120867-120872, 121295-121393, 121522-121755, 122041-122048. Inverted loop-associated excluded sites: 74668-74669, 88120-88128, 90474-90481, 94193-94205, 94696-94699, 97241-97245, 104712104716, $106631-106635$.

The aligned sequences were partitioned based on the chloroplast annotation of 116 functional genes, seven pseudogenes and two partitions that concatenated untranslated regions - 
266 one partition containing introns with secondary structure and the other concatenating all

267 intergenic sequences. The files that contained the introns were submitted to trimAl v1.2

268 (Capella-Gutiérrez, Silla-Martínez \& Gabaldón, 2009) to test different gap deletion settings.

269

270

271

272

273

274

275

276

277

278

279

280

281

282

283

284

285

286

287

288

289

290

291

292

293

294

295

\section{Faster region assessment}

We used the sequences from one sample on GenBank (FS1045) of Polystachya cultriformis and examined two published markers, $p s b D$-trnT (870 length aligned to our samples) and matK (1521 length aligned to our samples). We compared these sequences pairwise to one of our samples, $P$. estrelensis8, to check which was the faster-evolving region. We then ran a MrBayes v.3.2.4 (Ronqvist et al., 2012) analysis on the faster region, as a representative of a fast part of the chloroplast genome (fast cpDNA hereafter), with one copy of our dataset trimmed to this region alone plus the GenBank sequence.

We then ran successive analyses, using additional copies of the dataset interleaved in the same file, to explore the increase in support with an increase of characters evolving under the same model. This was to discover how much of the fast cpDNA data would be needed to achieve high support on most nodes in the phylogeny (i.e., among species but not necessarily within species). An important assumption we made at this stage was that the single fast region would contain mutations spread across most/all branches of the phylogeny. If this assumption was true, then a single region could carry changes representative of the entire phylogenetic history that we were exploring. The assumption is essentially one of i.i.d. (independently and identically distributed sites) - in that the sites would be representative of many unsampled sites and that double mutations would be rare - coupled with a sufficient dataset size to contain enough changes overall to reflect the history. Although the i.i.d. assumption is rarely true across sites, model-based analysis methods can cope with this, because the frequency of site patterns can be modelled by an i.i.d. process (Steel and Penny, 2000). So we are in effect mainly testing whether the original data set size was sufficient to carry changes reflective of the entire phylogeny under investigation.

\section{Random sample from all non-coding regions}

A single region copied many times proved ineffective in recovering most nodes with support (see Results). We therefore explored using random samples of characters without replacement from among all of the non-coding regions in our dataset to test how much data from 
296 faster regions would yield supported trees across most nodes. We expected this approach to be

297 less subject to the limitations caused by the stochastic nature of mutations coupled with the

298 limited size of any one region. By sampling across many regions (over $58 \mathrm{~kb}$ in this case), even

299 those few characters that have changed on short branches might be sampled occasionally. In

300 contrast, a single region, by chance, may simply not contain any characters changing on a

301 specific short branch.

302 We sampled without replacement $4 \%, 8 \%$ and $16 \%$ of the non-coding data using delete-

303 fraction jackknifing in the seqboot program v3.69 (from

304 http://evolution.genetics.washington.edu/phylip.html), excluding the poorly aligned parts and

305 with down-weighting of the inverted loops (by excluding all but one character of each loop), in

30620 replicates each. The approximate average (and range) of PP per clade was taken across the 20

307 replicates to get an indication of the likely support for selected clades that a non-coding dataset

308 of these sizes would generate. These values were plotted on the whole alignment analysis to

309 compare to the support received when using the whole dataset. Given that the largest dataset we

310 used here (hereafter the " $16 \%$ dataset", or $\sim 9.2 \mathrm{~kb}$ ) failed to recover support for all nodes found

311 in the whole genome analysis (see Results), we did not end up analysing the smaller replicates.

\section{Phylogenetic analysis}

313 MrBayes v.3.2.4 analyses were used for phylogenetic inference. These analyses were run

314 for five million generations (two million for the random sample replicates), using a mixed

315 substitution model (plus gamma and invariant sites) to account for among-site rate variation.

316 Priors on branch lengths were set to unconstrained: exponential (100) to minimise the chance of

317 inferring incorrectly long branches (Marshall, 2010), otherwise with default settings. The paired

318 runs were checked for convergence and high effective samples sizes in the MrBayes output and

319 Tracer v.1.6 (Rambaut et al., 2014), respectively. Burn-in generations were removed by

320 discarding $10 \%$ of the samples of parameters and trees, while summarising in TreeAnnotator

321 v.1.8 (Rambaut and Drummond, 2010) to ascertain clade posterior probabilities. Trees were

322 rooted using the Phalaenopsis sequence. Analyses using the character partitions were also done,

323 returning nearly identical results to the analysis described above, so they are not reported further. 


\section{RESULTS}

326

Our NGS approach allowed the capture of coding and non-coding regions throughout the

327

328

329

330

331

332

333

334

335

336

337

338

339

340

341

342

343

344

345

346

347

348

349

350

351

352

353

chloroplast genome. We recovered approximately $132 \mathrm{~kb}$, after the exclusion of gaps, representing 116 genes, seven pseudogenes, as well as regions with intergenic sequences and introns with secondary structure. Compared to the reference annotation, seven genes contained frameshifts that are usually associated with pseudogenisation and corresponded to previously reported pseudogenised genes in orchids (Luo et al., 2014).

We excluded eight of the 48 samples due to the low quality of the sequencing results (Table1). These eight samples showed lower DNA concentrations after the genomic library construction assembly, which may be the cause of low quality sequencing. The remaining 40 samples were submitted to the EMBL/ENA database under accession numbers ERS2203551ERS2203590. The coding regions have 48,308 polymorphic sites $(38,4 \%)$. Introns with secondary structure and regions with intergenic sequences have 21,264 (16,9\%) and 56,226 $(44,7 \%)$ polymorphic sites, respectively. The alignment of the concatenated data showed an unbalanced (but fairly typical) mean nucleotide composition of $A=29,9 \%, C=19,9 \%, G=19,4 \%$ e $\mathrm{T}=30,8 \%$.

\section{Analysis Results}

\section{Hairpin inversions}

In the non-coding part of alignment, we found evidence for eight putative small inversions (Table 2), based on the presence of inverted repeated motifs that could form stems at least four bp long. Stems of this length or longer are part of models of group II structures (Michel, Umesono \& Ozeki, 1989; Toor, Hausner \& Zimmerly, 2001; Kelchner, 2002) and are consistent with sequence patterns observed by one of us in the $r p L 16$ intron sequences in other taxa (Pfeil et al., 2002).

\section{Faster region assessment}

The pairwise identity between Polystachya concreta5 and P. concreta8 (whose common ancestor is relatively old and near the crown of Polystachya) for $p s b D$-trnT was $98.7 \%$. The pairwise identity for these samples for matK was 99.2\%. PsbD-trnT was therefore used as the 
354 representative fast cpDNA region. The analysis with a single copy of this dataset (870 bp)

355 yielded a MCC tree (Fig. 2A) with only five nodes with high support ( $>0.95 \mathrm{PP})$. Increasing the

356 number of copies did not result in much improvement. The analysis using 16 copies of $p s b D$ -

$357 \operatorname{trnT}(\sim 14 \mathrm{~kb})$ produced a MCC tree (Fig. $2 \mathrm{~B})$ containing only eight highly supported nodes.

358

359

360

361

362

363

364

365

366

367

368

369

370

371

372

373

374

375

376

377

378

379

380

381

382

\section{Random sample from all non-coding regions}

The pairwise identity between Polystachya concreta 5 and $P$. concreta 8 was $98.7 \%$ across $58236 \mathrm{bp}$ of non-coding region contained in our alignment. This compares to $98.8 \%$ identity between the same samples across the coding regions in our alignment.

The replicate datasets that sampled $16 \%$ of the original non-coding alignment (excluding poorly aligned parts and down-weighting the inverted loops) failed to return all nodes/clades found in the whole genome analysis. Of 13 selected nodes found in the tree from the whole genome (four subtended by relatively long branches, four by medium length branches, and five by short branches), only five were found with high support across most or all replicates (i.e., at least 16 of 20 replicates had $\geq 0.95 \mathrm{PP}$ ). Three of the selected nodes instead had five or fewer replicates with high support $(\geq 0.95 \mathrm{PP})$, but only one or no replicates that contained highly supported contradictory nodes (thus the support for the expected node was $\leq 0.05$ ). Finally, five of the nodes had generally poor support among replicates (i.e., five or fewer replicates had $\geq 0.95$ PP along with six or more replicates with $\leq 0.05$ PP for these nodes). The $16 \%$ datasets ( $\sim 9.2 \mathrm{~kb}$ ) recovered from seven to 21 highly supported nodes among replicates (mean=14.8), with more nodes recovered in 19 of 20 replicates than was the case with the larger repeated $p s b D$-trnT dataset ( $\sim 14 \mathrm{~kb}$ and eight supported nodes). This character sampling strategy was probably more reflective of the underlying support for various nodes than using repeated copies of a single small dataset.

The mutually exclusive foliosa1/concreta2 versus foliosa1/foliosa2 clades (see below) were also examined in the $16 \%$ datasets. In the first case (foliosa1/concreta2), just four replicates contained this clade with high or moderate support $(\geq 0.90 \mathrm{PP})$. The contradictory second grouping (foliosa1/foliosa2) was found with a similar level of support ( $\geq 0.90 \mathrm{PP})$ in only two replicates. The fact that both groupings could be recovered, with high support, in at least some replicates suggests that the original dataset contains the signal of both clades. A NeighborNet 
383 analysis (Fig. 3B) confirmed that a mixture of patterns exists in the original dataset involving

384 foliosa1, foliosa2, concreta1 and concreta2.

385

386

387

388

389

390

391

392

393

394

395

396

397

398

399

400

401

402

403

404

405

406

407

408

409

410

411

\section{Phylogenetic analyses}

Analyses with and without the inverted loops (the latter by down-weighting to a single character) returned almost identical trees. The results of only the latter analysis is presented in this section. The tree we recovered was able to resolve the phylogenetic relationships among the groups of the large clade selected for this study, with high support values on almost every node (Fig. 3). The tree was characterized by a large clade with relatively short branches containing only sequences from the Neotropics, with a grade of a few small clades and single sequences containing the remaining sequences (Fig. 3). The large clade contained 21 sequences from Brazil, Dominica and Venezuela, whereas the grade included 19 sequences from tropical central and eastern Africa, as well as Madagascar and the nearby islands (Fig. 3).

The grade recovered include a few geographically identifiable clades (Fig. 3). One of these, attaching fairly deeply within the crown, consists of four Malagasy sequences

(Polystachya humbertii1, P. humbertii2, P. oreocharis and P. tsinjoarivensis2) that are sister to a Kenyan sequence ( $P$. eurychila). Another clade comprises a Kenyan sequence ( $P$. golungensis) and one from Reunion (P. concreta 8$)$. A third clade contains a pair of central African sequences, one from Cameroon ( $P$. odorata 2$)$ and one from Nigeria $(P$. odorata 1$)$. A fourth clade contains sequences from central Africa ( $P$. concreta 5 from Cameroon), Madagascar ( $P$. tesselata 1$)$, the Comoros (P. concreta9) and two sequences without certain provenance. Finally, a fifth pair of sequences were from samples collected from Mauritius ( $P$. concreta 7$)$ and Madagascar $(P$. tesselata2). Lineages containing only a single sequence in this grade included samples from Kenya (P. melanantha and P. steudneri) and Cameroon ( P. dolichophylla).

Sequences from the widely sampled and widely distributed $P$. concreta did not form a monophyletic group and occurred on different branches of the tree, separated by several well supported nodes (Fig. 3). Similarly, the two P. tessellata sequences from Madagascar did not form a clade. Polystachya estrellensis sequences form a clade with $P$. concreta sequences collected in Brazil. Although the sequences of $P$. estrellensis are thus paraphyletic, whether the taxon itself is paraphyletic cannot be established for certain here. The identification of this $P$. 
412 concreta sample could be wrong, given that the identification of these species is confused in

413 Brazil and sometimes they are considered synonymous (see also Discussion).

414

415

416

417

418

419

420

421

422

423

424

425

426

427

428

429

430

431

432

433

434

435

436

437

438

439

440

\section{With versus without loops}

The down weighting of the inversions we identified (by excluding all but one character per inversion) resulted in a similar, but not identical, phylogenetic inference. The differences among the maximum clade credibility (MCC) trees involved P. foliosal, P. foliosa2, $P$. concreta $1, P$. concreta $2, P$. concreta 3 and $P$. concreta4. The analysis with the inversions included returned this tree (Fig. 3A and Fig. 4A):

((concreta3, concreta4):1,((foliosa1,foliosa2):0.98,(concreta1,concreta2):0.98):0.97) with clade posterior probabilities (PP) listed after each node. In contrast, the inference resulting from down-weighted inversions returned this tree (Fig. 3 main panel and Fig. 4 main panel):

((foliosa1,concreta2):1,((concreta3,concreta4):1,(foliosa2,concreta1):0.76):1)

There are several supported differences between these trees, with at least one corresponding to the way the inverted loops are weighted. When the entire loops are analysed, $P$. foliosa 1 and $P$. foliosa 2 are supported as sisters, with these two sequences appearing to share two loop inversions (if this topology is correct; Fig. 4A). However, down-weighting the inversions produces a tree consistent instead with two independent inversions (Fig. 4 main panel).

\section{DISCUSSION}

Chloroplast genome sequence provides a robust phylogeny

In this work we used the nearly complete chloroplast sequences of 40 Polystachya samples to infer a robust plastid phylogeny. The dataset significantly increased the phylogenetic resolution within the genus. Thus, our results suggest that increasing the number of molecular markers has the potential to solve not only the relationships among species, but also to identify new Polystachya clades and define new sections. The delimitation of new sections will, however, depend upon the inclusion of more taxa than was done by this study - in other words a higher coverage of the genus. Below we highlight some of the clades recovered, their morphological and/or geographical characterisation, and a comparison with previous studies. 


\section{Polystachya bicolor/rosea position contradicts Russell's Clade III}

Of the two species selected as possible distant relatives to provide more context in the phylogenetic inference, one of them, $P$. bicolor $(=P$. rosea $)$, appears in a clade together with samples of $P$. concreta (from Cameroon and from the Comoros), P. tesselata (= P. concreta) and $P$. modesta. Not surprisingly, the clade that includes $P$. bicolor/rosea is deeply nested within the ingroup, thus contradicting the monophyletic Clade III presented by Russell et al. (2010 b).

In prior studies, Polystachya bicolor/rosea has an uncertain position in the phylogenetic trees. In an analysis using plastid markers and Bayesian inference, this species appears in a large polytomy with P. concreta and other related species (Mytnik-Ejsmont, 2011), or related to species of other clades (Russell et al., 2010b) depending on the marker used. A phylogeny using nuclear data (ITS sequences) highlighted the lack of monophyly of this species (MytnikEjsmont, 2011), which may be connected to the difficulty in identifying it. Polystachya bicolor/rosea is often mistaken for $P$. concreta, since differentiation between these is made by subtle differences in the shapes of leaves, and the size and colour of the flowers. Unlike $P$. concreta, which has a pantropical distribution, P. bicolor/rosea is restricted to Madagascar, Comoros and the Seychelles (Mytnik-Ejsmont, 2011).

\section{Brazilian sequences form a clade}

The monophyletic nature of the group formed by the Brazilian accessions, contrasting with the paraphyletic group made up of African accessions, is consistent with the hypothesis that Africa is the centre of origin with a subsequent (i.e., more recent) dispersal into the Neotropics (Russell et al., 2010 a; Russell et al., 2010b).

\section{Hybrid origins of some taxa suggested}

The hybrid origin of $P$. concreta is a possible explanation for this species being found in different positions in the tree (Russell et al., 2010b). Polystachya concreta individuals that have dispersed out of Africa are tetraploid, whereas plants found in continental Africa can be diploid or tetraploid. The sister taxa of African P. concreta are diploid (Russell et al., 2010b), indicating that tetraploidy is a derived state in $P$. concreta. Allotetraploidy in P. concreta has been confirmed by analysis of low copy nuclear genes (Russell et al., 2010a).

Interspecific hybridisation events, as in P. concreta, are considered a source of chloroplast genome exchange via introgression. Chloroplast genome exchange among species is 
471 sometimes suggested as an explanation for the inconsistencies between phylogenetic trees based 472 on nuclear and plastid markers in, e.g., Populus (Salicaceae) (Smith \& Sytsma, 1990; Tsitrone, 473 Kirkpatrick \& Levin, 2003), Nothofagus (Nothofagaceae) and Crassulaceae (Mort et al., 2002;

474 Acosta \& Premoli, 2010). In Nothofagus, chloroplast capture results in the association of 475 chloroplast genomes with geographic locations, rather than taxonomic relationships (Acosta \& 476 Premoli 2010). Relationships based on geographic location could be explored as a possible 477 explanation for the proximity of $P$. concreta (accesses from Brazil) with P. estrellensis (also 478 from Brazil) and not with non-Brazilian accessions of P. concreta. In this case a study of nuclear 479 markers of these taxa would be needed.

480

481

482

483

484

485

486

487

488

489

490

491

492

493

494

495

496

497

498

499

500

\section{Neotropical species}

Relationships in the group that includes $P$. concreta, $P$. foliosa, $P$. estrellensis and other species are not well resolved due to the low sequence divergence levels between species found in both plastid and nuclear genes (Russell et al., 2010a; Russell et al., 2010b; Russell et al., 2011; Mytnik-Ejsmont, 2011). Generally, the morphological variation observed in this group is identified as $P$. concreta. Although $P$. estrellensis is considered a valid species on the official plant list of Brazil (Barros et al., 2010), there is no consensus on synonymy with P. concreta. This can be seen in the herbarium identifications that sometimes consider them as two distinct species, but sometimes as the same species. The same occurs with $P$. foliosa, a name which would only be correctly applied to plants from the Amazon basin, the Guyana Shield and the West Indies (Peraza-Flores, Fernández-Concha \& Romero-González, 2011). This circumscription is not accepted by Mytnik-Ejsmont (2011), who considers $P$. estrellensis and $P$. foliosa to be synonymous.

Genetic dissimilarity between African and Neotropical tetraploids was reported by Russell et al. (2010) and Russell et al. (2011), but the delimitation P. estrellensis, P. concreta and $P$. foliosa remained uncertain. According to our results, under a molecular perspective, $P$. estrellensis should be considered distinct from P. concreta. Moreover, our results do not corroborate the placement in synonymy of $P$. estrellensis and P. foliosa as proposed by MytnikEjsmont (2011). In our tree $P$. foliosa forms a highly supported group with some $P$. concreta sequences (from samples collected in Brazil). Finally, although our results indicate a possible separation of Brazilian and African P. concreta, the delimitation of this species remains 
501 uncertain, considering that there is no generic taxonomic revision that has rigorously analysed

502 the morphological variation in this species. Moreover, considering the reticulated evolution by

503 Russell et al. (2010a), further investigation with nuclear markers would be necessary.

$504 \quad$ Taken together, our analysis suggests that $P$. estrellensis can be considered a distinct

505 species from P. concreta and P. foliosa, and that Brazilian and African P. concreta should

506 probably be treated as different species. Evidence of hybridisation influencing the evolution of $P$.

507 concreta (Russell et al., 2010a; Russell et al., 2010b) highlights how importance it will be to also

508 consider bi-parentally inherited nuclear DNA when inferring of phylogenetic relationships

509 between this species and other species of the genus. The placement in synonymy of $P$.

510 estrellensis and P. foliosa proposed by Mytnik-Ejsmont (2011) was not confirmed by this study.

511 In our results, $P$. foliosa forms a highly supported clade including Brazilian samples of $P$.

512 concreta.

513

514 Implications for Data Requirements

515

516

517

518

519

520

521

522

523

524

525

526

527

528

529

530

\section{The entire chloroplast is more useful than a fast subset}

By using a relatively large number of chloroplast sequences we were able to resolve the polytomy involving the Neotropical species. But, if on one hand this dataset is promising in the formulation of more robust phylogenetic hypotheses, on the other hand, the complete chloroplast genome sequencing may be costly for systematic projects that consider genera with many species (Särkinen \& George, 2013), such as Polystachya, which has about 250 species. This was the main motivation for testing how well a smaller sample of the chloroplast genome would perform in phylogenetic inference. This was done in two ways: by duplicating a fast region and analysing multiple copies of this dataset, and by sampling without replacement from all non-coding regions in our alignment.

We found that sampling without replacement up to $\sim 9 \mathrm{~kb}$ of non-coding sequence (16\% of our alignment) was not sufficient to return a robust inference across all nodes. This was in contrast to the analysis of the entire chloroplast and showed that in the case of these samples of Polystachya, more data were needed to resolve their relationships. The cost of primers, amplification and Sanger sequencing of only three or four regions begins to exceed that of gene capture of the entire chloroplast. It is therefore more cost effective and produces a more robust 
531 result to undertake the collection of the entire chloroplast genome. That said, our $16 \%$ sample

532 did resolve some nodes with high support, and other nodes obtained moderate to high support

533 from a few of the replicates. This suggests that these data are on the way to resolving most

534 nodes, but a gradual increase in resolving power occurs as characters are added.

535 Duplicating a single fast region even 16 times, in this case $p s b D$-trnT copies totalling $\sim 14$

$536 \mathrm{~kb}$, failed to achieve a robustly resolved phylogeny. The results for the $p s b D$-trnT duplicated

537 analysis was poorer even than that of sampling fewer but more representative characters across

538 the non-coding region (above). It appears that a small sample size (only $870 \mathrm{bp}$ of independent

539 sequence sites) is a serious source of stochastic error in this case. Sampling one versus 16 copies

540 of the same dataset only slightly increased the number of resolved nodes (but still falling short of

541 the number of nodes usually resolved with support by the smaller $16 \%$ sample), confirming the

542 limitations of the original dataset. It is likely that the original dataset simply did not contain sites

543 that changed on most branches of the phylogeny during the span of history that we investigated.

$544 \quad$ Numerous previous studies have also examined which regions of the plastid genome are

545 typically evolving faster than others (e.g., Small et al., 1998; Shaw et al., 2005; Shaw et al.,

546 2007; Shaw et al., 2014). Prior to NGS methods, the aim was to identify the "best" regions, when

547 sequencing only a limited number could be afforded in most projects. However, given current

548 technology, we should shift our focus to whether a few of the "best" regions are cost effective

549 compared to using the entire genome, as the latter has become affordable for even small

550 phylogenetic projects.

\section{Homoplastic hairpin inversions affect phylogenetic analysis}

552

One issue raised here that is rarely taken into account in analyses of whole chloroplasts is that sequence patterns at the small scale, namely hairpin inversions of loops, can still have an effect on phylogenetic inference, despite using very large data sets. Our results indicate that at least some of the differences between the trees inferred using entire loops versus down-weighted loops were driven by these hairpin loop inversions. This kind of phylogenetic effect has been observed in other cases, although with smaller data sets (e.g., Kim and Lee, 2005; Joly et al., 2010). If loops invert in a single molecular event (as is currently believed: Kelchner and Wendel, 1996; Kim and Lee 2005), such as an intra-molecular recombination, then there is no good reason to use each character state difference found between sequences in the entire loop in an 
561 analysis. This simply inflates the phylogenetic impact of a single event, treating it instead as

562 many independent events (corresponding to the number of character state differences in the

563 inversion), as also noted by Kim and Lee (2005). As shown here, a larger data set simply does

564 not give licence to ignore known analytical pitfalls.

565 Together, these findings show that sampling the entire chloroplast, analysed carefully, is

566 a better option than sampling a few (even a dozen or more) fast regions. This is true, at least in

567 Polystachya, but a similar result has also found by other studies, such as Parks, Cronn. \& Liston

568 (2009) for Pinus. Based on cost alone, it seems there is no benefit to be gained by screening the

569 chloroplast for faster markers when there are many short branches in the particular tree, as there

570 are here. Whole chloroplast analyses are likely to be a better way forward than sampling

571 individual chloroplast markers in addressing many phylogenetic questions. If gene capture is

572 used, as it was here, it is also very easy to add probes to unlinked nuclear regions, further

573 increasing the power of this approach as a general solution to the issue of data sampling.

574

575

\section{CONCLUSIONS}

576

Our results show that significantly increasing the number of nucleotides can be an

577

effective option in the phylogenetic inference of taxonomic challenging taxa, such as the orchid

578 genus Polystachya. We generated complete chloroplast sequences of 40 Polystachya specimens

579

using a combination of Illumina NGS sequencing and a sequence capture, which solved a

580

notorious polytomy for Neotropical species. Our tests on how well a smaller sample of the

581

chloroplast genome would perform in phylogenetic inference shows that the whole chloroplast is

582

a better option than selecting just a few highly variable markers. Full plastid genomes appear

583 particularly powerful when the expected tree is likely to contain many short branches, but nonetheless need to be analysed with care.

\section{ACKNOWLEDGEMENTS}

587

We thank our colleagues in our research groups for discussions, advice and support

588 throughout this project. We also thank the anonymous reviewers whose comments helped improve the paper. 


\section{REFERENCES}

592

Acosta MC, Premoli AC. 2010. Evidence of chloroplast capture in South American

593

Nothofagus (subgenus Nothofagus, Nothofagaceae). Molecular Phylogenetics and Evolution 54:

594 235-242

595

596

597

598

599

600

601

602

603

604

605

606

607

Liu S-M, Chang C-C, Chaw S-M. 2006. The chloroplast genome of Phalaenopsis aphrodite

608

(Orchidaceae): comparative analysis of evolutionary rate with that of grasses and Its

609

phylogenetic implications. Molecular Biology and Evolution 23, 279-291

610

https://doi.org/10.1093/molbev/msj029

611

Christenhusz MJM, Byng JW. 2016. The number of known plants species in the world

612 and its annual increase. Phytotaxa 261: 201-217. http://dx.doi.org/10.11646/phytotaxa.261.3.1

613

614

Cribb PJ. 1978. Studies in the genus Polystachya (Orchidaceae) in Africa. Kew Bulletin

615

616

617

618 32: 743-766

Cronn R, Knaus BJ, Liston AP, Maughan J, Parks M, Syring JV, Udall J. 2012. Targeted enrichment strategies for next-generation plant biology. American Journal of Botany 99: 291-311

Daniell D, Lee S-B, Saski JGC, Guda TQ-VC, Tomkins J, Jansen RK. 2006. Complete chloroplast genome sequences of Solanum bulbocastanum, Solanum lycopersicum and 
619 comparative analyses with other Solanaceae genomes. Theoretical and Applied Genetics 112: $620 \quad 1503-1518$

621 Dressler RL. 1990. The Orchids: natural historyand classification. Cambridge: Harvard 622 University Press.

623 Dressler RL. 1993. Phylogeny and classification of the orchid family. Cambridge: 624 Cambridge University Press.

625 Eaton DAR, Ree RH. 2013. Inferring phylogeny and introgression using RADseq data: 626 an example from 347 flowering plants (Pedicularis: Orobanchaceae). Systematic Biology 62: $627 \quad 689-706$

628 Edwards SV. 2009. Is a new and general theory of molecular systematics emerging? 629 Evolution 63: 1-19

630 Freudenstein JV, Chase MW. 2015. Phylogenetic relationships in Epidendroideae 631 (Orchidaceae), one of the great flowering plant radiations: progressive specialization and 632 diversification. Annals of Botany 115: 665-681

633 Górniak M, Paun O, Chase MW. 2010. Phylogenetic relationships within Orchidaceae 634 based on a low-copy nuclear coding gene, Xdh: Congruence with organellar and nuclear 635 ribosomal DNA results. Molecular Phylogenetics and Evolution 56: 784-795

636 Gustafsson AL, Verola CF., Antonelli A. 2010. Reassessing the temporal evolution of 637 orchids with new fossil and a Bayesian relaxed clock, with implications for the diversification of 638 the rare South American genus Hoffmanseggella (Orchidaceae: Epidendroideae). Evolutionary 639 Biology 10:177

640 Joly S, Pfeil BE, Oxelman B, McLenachan PA, Lockhart PJ. 2010. A statistical approach 641 for distinguishing hybridisation and incomplete lineage sorting: correction. American Naturalist 642 175: 621-622

643 Kamneva OK, Syring J, Liston A, Rosenberg NA. 2017. Evaluating allopolyploid origins 644 in strawberries (Fragaria) using haplotypes generated from target capture sequencing. BMC 645 Evolutionary Biology 17(1):180. doi: 10.1186/s12862-017-1019-7

646 Katoh K, Standley DM. 2013. MAFFT multiple sequence alignment software version 7: 647 improvements in performance and usability. Molecular Biology and Evolution 30: 772-780 648 Kelchner SA. 2002. Group II introns as phylogenetic tools: structure, function, and 649 evolutionary constraints. American Journal of Botany 89: 1651-1669 
Kelchner SA, Wendel JF. 1996. Hairpins create minute inversions in non-coding regions

651

652

653

654

655

656

657

658

659

660

661

662

663

664

665

666

667

668

669

670

671

672

673

674

675

676

677

678

679

680

of chloroplast DNA. Current Genetics 30: 259-262

Kim K-J, Lee H-L. 2005. Widespread occurrence of small inversions in the chloroplast genomes of land plants. Molecules \& Cells 19: 104-113

Kraenzlin F. 1926. Monographie der Gattung Polystachya Hook. Repertorium Specierum Novarum Regni Vegetabilis, Beihefte 39: 1-136

Lemmon A, Emme S, Lemmon E. 2012. Anchored hybrid enrichment for massively high-throughput phylogenomics. Systematic Biology 61:727-744

Lemmon EM, Lemmon AR. 2013. High-throughput genomic data in systematics and phylogenetics. Annual Review of Ecology, Evolution and Systematics 44: 99-121

Li H, Handsaker B, Wysoker A, Fennell T, Ruan J, Homer N, Marth G, Abecasis G Durbin R. 2009. The Sequence Alignment/Map format and SAMtools. Bioinformatics 25: 20782079

Li C, Hofreiter M, Straube N, Corrigan S, Naylor GJP. 2013. Capturing protein-coding genes across highly divergente species. BioTechniques, 54: 321-326

Luo J, Hou BW, Niu ZT, Liu W, Xue QY, Ding XY. 2014. Comparative chloroplast genomes of photosynthetic orchids: insights into evolution of the Orchidaceae and development of molecular markers for phylogenetic applications. PLoS One 9: e99016

Mamanova L, Coffey AJ, Scott CE, Kozarewa I, Turner EH, Kumar A, Howard E, Shendure J, Turner DJ. 2010. Target-enrichment strategies for next generation sequencing. Nature Methods 7: 111-118

Marshall DC. 2010. Cryptic failure of partitioned Bayesian phylogenetic analyses: lost in the land of long trees. Systematic Biology 59: 108-117

McCormack JE, Hird SM, Zellmer AJ, Carstens BC, Brumfield RT. 2013. Applications of next-generation sequencing to phylogeography and phylogenetics. Molecular Phylogenetics and Evolution 66: 526-538

Michel F, Umesono K, Ozeki H. 1989. Comparative and functional anatomy of group II catalytic introns - a review. Gene 82: 5-30

Mort ME, Soltis DE, Soltis PS, Francisco-Ortega J, Santos-Guerra A. 2002.

Phylogenetics and evolution of the Macaronesian clade of Crassulaceae inferred from nuclear and chloroplast sequence data. Systematic Botany 27: 271-288 
681

682

683

684

685

686

687

688

689

690

691

692

693

694

695

696

697

698

699

700

701

702

703

704

705

706

707

708

709

710

Mytnik-Ejsmont J. 2011. A Monograph of the subtribe Polystachyinae Schltr.

(Orchidaceae). Koenigstein: Koeltz Scientific Books.

Parks M, Cronn R, Liston A. 2009. Increasing phylogenetic resolution at low taxonomic

levels using massively parallel sequencing of chloroplast genomes. BMC Biology 7:84

Peraza-Flores LN, Fernández-Concha GC, Romero-González GA. 2011. Taxonomic

notes in American Polystachya (Orchidaceae): the identity of P. foliosa (Hook.) Rchb.f. and the reestablishment of P. caracasana Rchb.f. Journal of the Torrey Botanical Society 138: 366-380

Pfeil BE, Brubaker CL, Craven LA, Crisp MD. 2002. Phylogeny of Hibiscus and the tribe Hibisceae (Malvaceae) using chloroplast DNA sequences of ndhF and the rpl16 intron.

Systematic Botany 27: 333-350

Pridgeon AM, Cribb PJ, Chase MW, Rasmussen FN (eds.). 2005. Genera

Orchidacearum, vol. 4, Epidendroideae, part 1. Oxford: Oxford University Press.

Rambaut A, Drummond AJ. 2010. TreeAnnotator version 1.6.1 http://beast.bio.ed.ac.uk

Rambaut A, Suchard MA, Xie D \& Drummond AJ (2014) Tracer v1.6, Available from http://tree.bio.ed.ac.uk/software/tracer/

Ramírez SR, Gravendeel B, Singer RB, Marshall CR, Pierce NE. 2007. Dating the origin of the Orchidaceae from a fossil orchid with its pollinator. Nature 448: 1042-1045. doi:10.1038/nature06039

Ramírez SR, Eltz T, Fujiwara MK, Gerlach G, Goldman-Huertas B, Tsutsui ND, PierceNE. 2011. Asynchronous Diversification in a Specialized Plant-Pollinator Mutualism. Science 333: 1742-1746. DOI: 10.1126/science.1209175

Ronquist F, Teslenko M, van der Mark P, Ayres D, Darling A, Höhna S, Larget B, Liu L, Suchard MA, Huelsenbeck JP. 2012. MrBayes 3.2: Efficient Bayesian phylogenetic inference and model choice across a large model space. Systematic Biology 61:539-542

Rupp B, Samuel R, Russell A, Temsch EM, Chase MW, Leitch IJ. 2010. Genome size in Polystachya (Orchidaceae) and its relationships to epidermal characters. Botanical Journal of the Linnean Society 163: 223-233

Russell A, Samuel R, Klejna V, Barfuss MHJ, Rupp B, Chase MW. 2010 (a). Reticulate evolution in diploid and tetraploid species of Polystachya (Orchidaceae) as shown by plastid DNA sequences and low-copy nuclear genes. Annals of Botany 106: 37-56 
Russell A, Samuel MR, Rupp B, Barfuss MHJ, Šafran M, Besendorfer V, Chase MW.

712

713

714

715

716

717

718

719

720

721

722

723

724

725

726

727

728

729

730

731

732

733

734

735

736

737

738

739

740

741

2010 (b). Phylogenetics and cytology of a pantropical orchid genus Polystachya (Polystachyinae;

Vandeae; Orchidaceae): evidence from plastid DNA sequence data. Taxon 59: 389-404

Russell A, Samuel R, Bogarín D, Fernando S, Wijesundera S, Klejna V, Chase MW.

2011. Genetic variation and phylogenetic relationships of a pantropical species group in

Polystachya (Orchidaceae). Botanical Journal of the Linnean Society 165: 235-250

Särkinen T, George M. 2013. Predicting plastid marker variation: can complete plastid genomes from closely related species help? PLoS One 8: e82266

https://doi.org/10.1371/journal.pone.0082266

Shaw J, Lickey EB, Beck JT, Farmer SB, Liu W, Miller J, Siripun KC, Winder CT, Schilling EE, Small RL. 2005. The tortoise and the hare II: relative utility of 21 noncoding chloroplast DNA sequences for phylogenetic analysis. American Journal of Botany 92:142-166

Shaw J, Lickey EB, Schilling EE, Small RL. 2007. Comparison of whole chloroplast genome sequences to choose noncoding regions for phylogenetic studies in angiosperms: the tortoise and the hare III. American Journal of Botany 94:275-288

Shaw J, Shafer HL, Leonard OR, Kovach MJ, Schorr M, Morris AB. 2014. Chloroplast DNA sequence utility for the lowest phylogenetic and phylogeographic inferences in angiosperms: the tortoise and the hare IV. American Journal of Botany 101:1987-2004

Small RL, Ryburn JA, Cronn RC, Seelanan T, Wendel JF. 1998. The tortoise and the hare: choosing between noncoding plastome and nuclear Adh sequences for phylogeny reconstruction in a recently diverged plant group. American Journal of Botany 85:1301-1315

Smith RL, Sytsma KJ. 1990. Evolution of Populusnigra (sect.Aigeiros): introgressive hybridisation and the chloroplast contribution of Populusalba (sect. Populus). American Journal of Botany 77(9): 1176-1187

Song S, Liu L, Edwards SV, Wu S. 2012. Resolving conflict in eutherian mammal phylogeny using phylogenomics and the multispecies coalescent model. Proceedings of the National Academy of Sciences, USA 109: 14942-14947. doi: 10.1073/pnas.1211733109

Sousa F, Bertrand YKJ, Nylinder S, Oxelman B, Eriksson JS, Pfeil BE. 2014.

Phylogenetic properties of 50 nuclear loci in Medicago (Leguminosae) generated using multiplexed sequence capture and next-generation sequencing. PLoS One 9(10):e109704. doi: 10.1371/journal.pone.0109704 
Steel, M, Penny, D. 2000. Parsimony, likelihood, and the role of models in molecular phylogenetics. Molecular Biology and Evolution 17:839-850.

744 doi:10.1093/oxfordjournals.molbev.a026364

745

746

747

748
Stephens JD, Rogers WL, Heyduk K, Cruse-Sanders JM, Determann RO, Glenn TC, Malmberg RL. 2015. Resolving phylogenetic relationships of the recently radiated carnivorous plant genus Sarracenia using target enrichment. Molecular Phylogenetics \& Evolution 85:76-87. doi: 10.1016/j.ympev.2015.01.015

Summerhayes VS. 1942. African orchids: XII. Botanical Museum Leaflets 10: 257-299 Summerhayes VS. 1947. African orchids: XVII. Kew Bulletin 2: 123-133

Timme RE, Kuehl JV, Boore JL, Jansen RK. 2007. A comparative analysis of the Lactuca and Helianthus (Asteraceae) plastid genomes: Identification of divergent regions and categorization of shared repeats. American Journal of Botany 94: 302-312

Toor N, Hausner G, Zimmerly S. 2001. Coevolution of group II intron RNA structures with their intron-encoded reverse transcriptases. $R N A$ 7: 1142-1152

Tsitrone A, Kirkpatrick M, Levin DA. 2003. A model for chloroplast capture. Evolution 57: $1776-1782$

Van den Berg C, Goldman DH, Freudenstein JV, Pridgeon AM, Cameron KM, Chase MW. 2005. An overview of the phylogenetic relationships within Epidendroideae inferred from multiple DNA regions and recircumscription of Epidendreae and Arethuseae (Orchidaceae). American Journal of Botany 92: 613-624Weitemier K, Straub SCK, Cronn RC, Fishbein M, Schmickl R, McDonnell A, Liston A. 2014. Hyb-Seq: Combining target enrichment and genome skimming for plant phylogenomics. Applications in Plant Sciences 2(9), 1400042 
Figure 1

Distribution of Polystachya and the location of samples used in this study.

Grey shading shows the distribution of the genus. Coloured symbols show the location of samples used here, with the species determination of each sample as per Table 1.

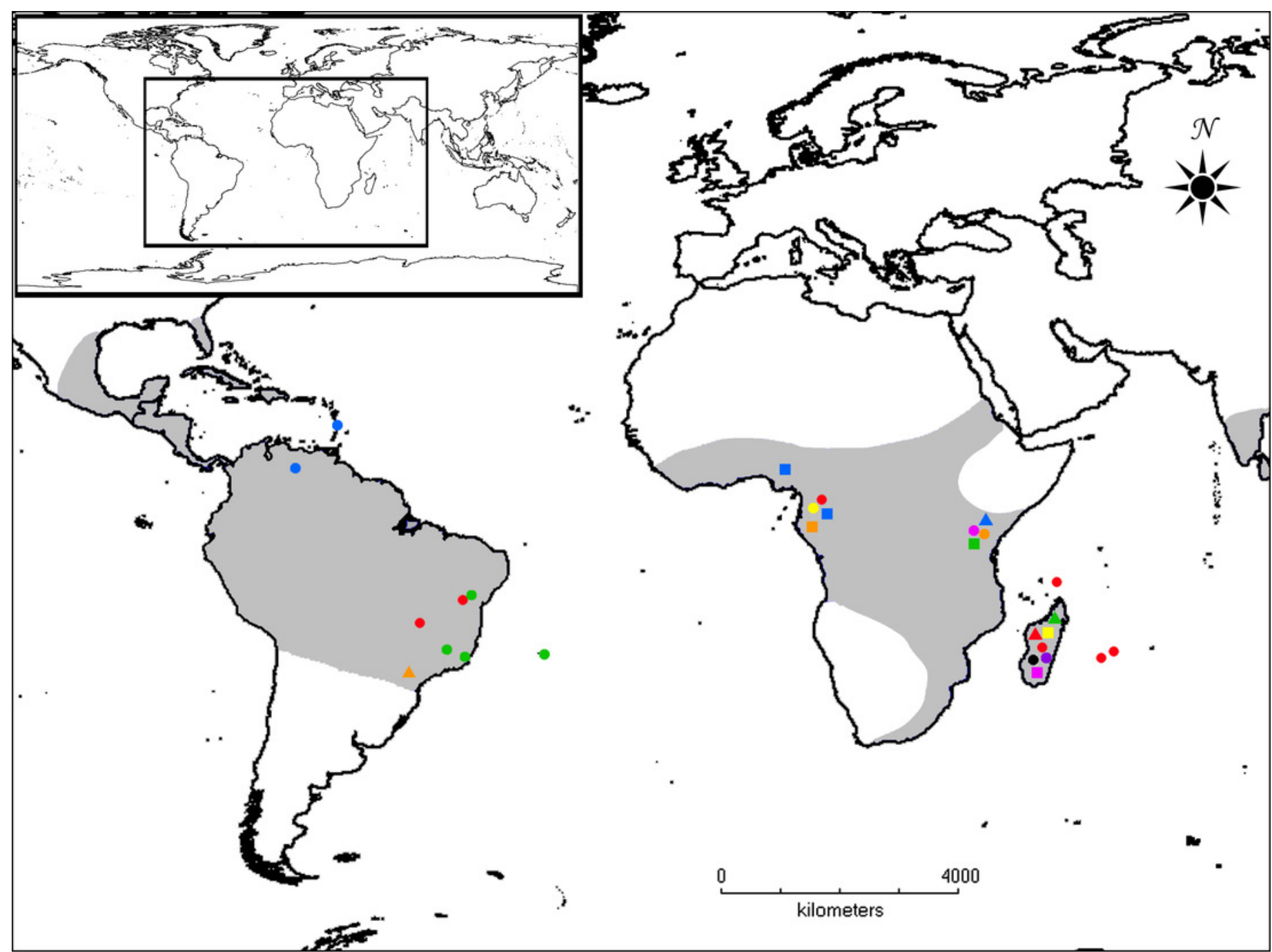

Polystachya concreta

Polystachya cornigera

Polystachya dolicophylla

Polystachya estrellensis

Polystachya eurychila

Polystachya foliosa
Polystachya golungensis

Polystachya henrici

Polystachya humbertii

Polystachya melanantha

Polystachya odorata

Polystachya oreocharis
Polystachya paniculata

Polystachya pinicola

- Polystachya steudneri

- Polystachya tessellata

$\Delta$ Polystachya tsinjoarivensis 


\section{Figure 2}

Phylogeny of the psbD-trnT region estimated using Bayesian analysis and rooted using Phalaenopsis aphrodite.

Posterior probabilities are show above branches. Scale bar is in substitutions per site. The two branches leading to the root have been foreshortened to reduce space and are thus not to scale. (A) Phylogeny based on a single copy of psbD-trnT. (B) Phylogeny based on 16 identical copies of the $p s b D$-trnT data set. 
A
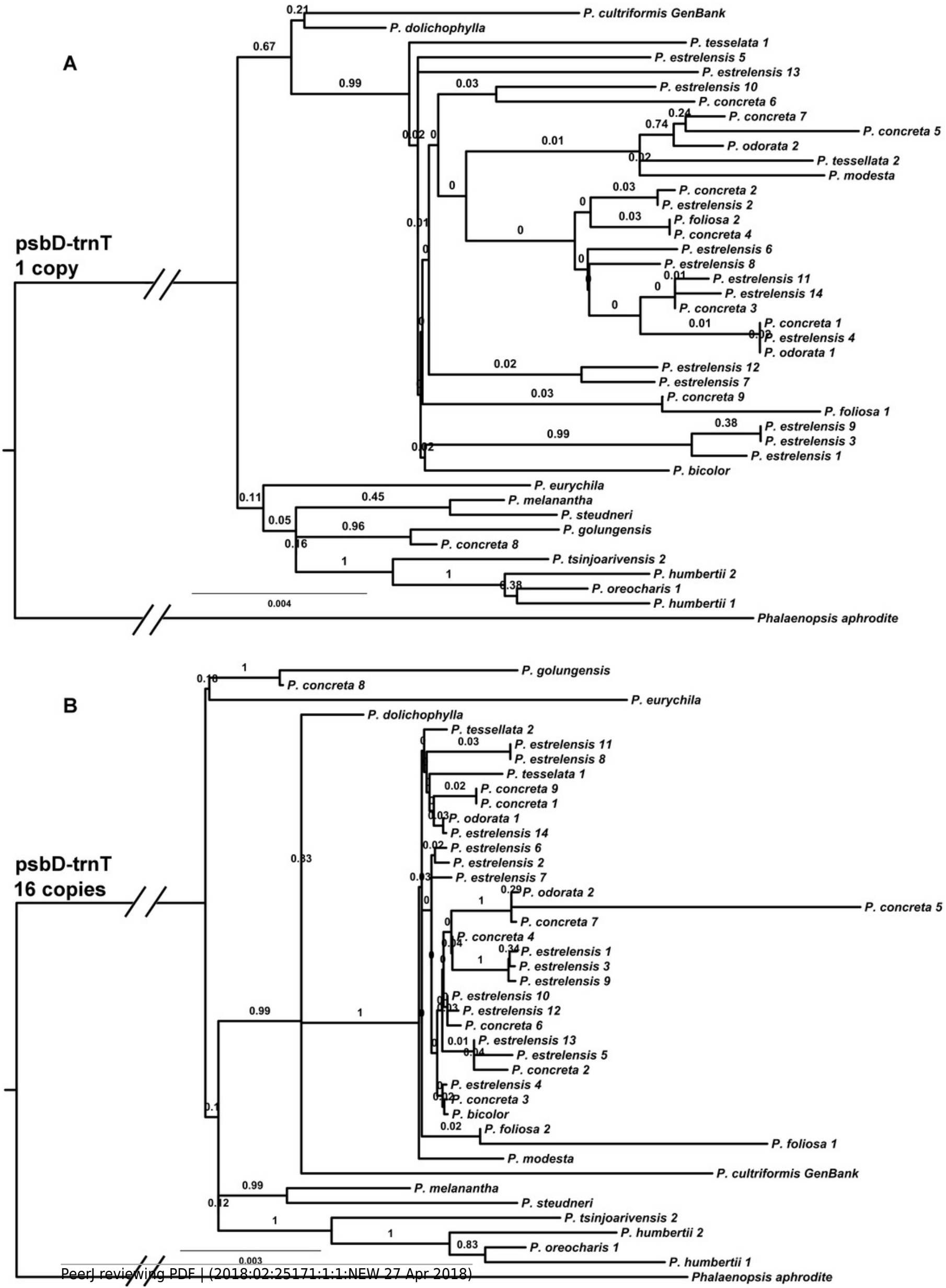
Figure 3

Plastid phylogeny from Bayesian analysis rooted using Phalaenopsis aphrodite.

Posterior probabilities are show above branches. The Polystachya estrelensis group has been collapsed to reduce detail. Scale bar is in substitutions per site. The two branches leading to the root have been foreshortened to reduce space and are thus not to scale. The two insets are not at the same scale as the main figure. Main Figure: Phylogeny based on the data set with poorly aligned regions excluded and loops down-weighted. (A) (in grey) Phylogeny of the foliosa/concreta group based on the full inclusion of loops. (B) (in black) NeighborNet network of the foliosa/concreta group based on the down-weighted loops. Polystachya estrelensis photo credit: N. Lopes de Abreu.

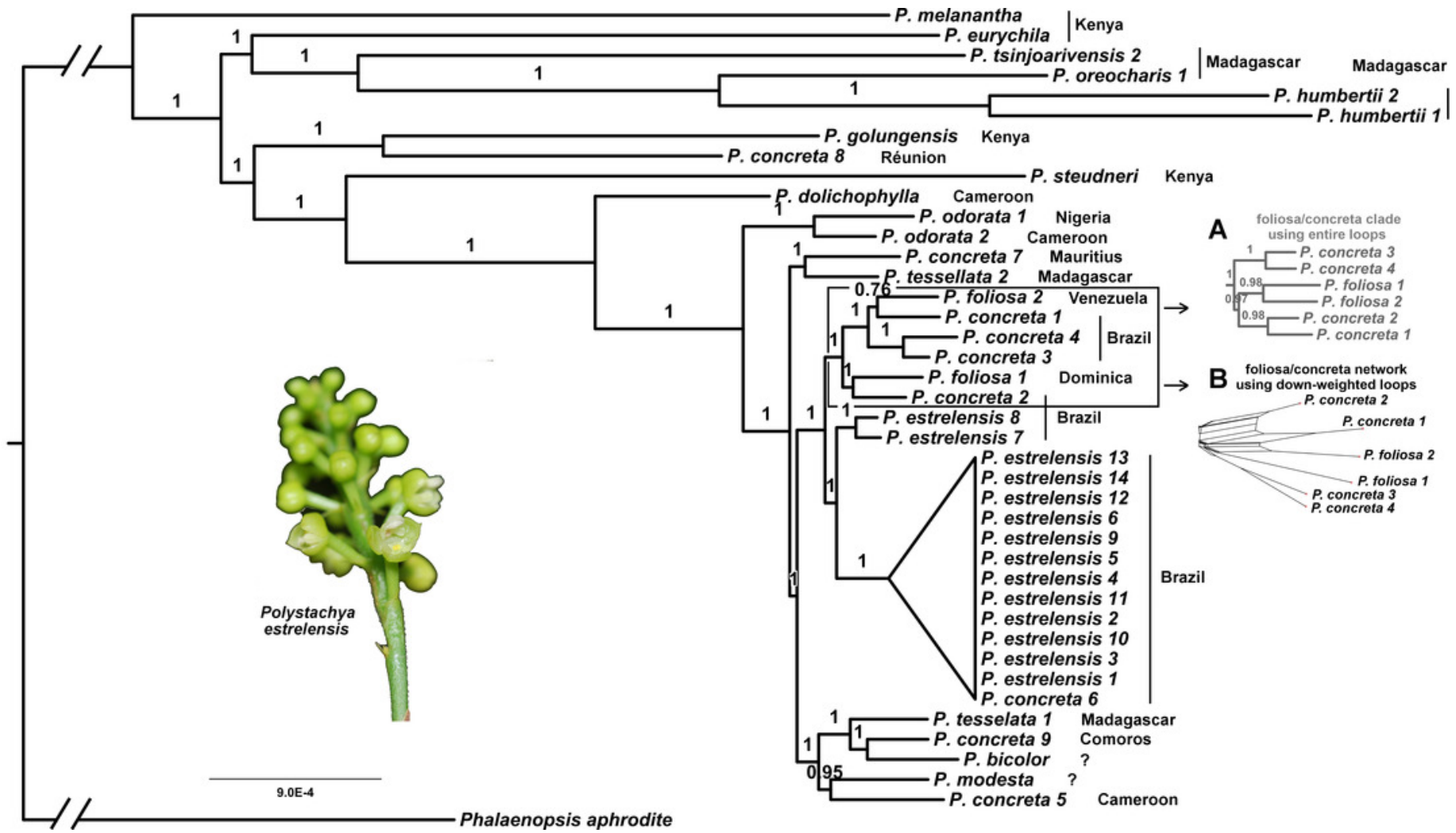




\section{Figure 4}

Parsimonious gains and losses of non-coding loop inversions in Polystachya relative to the outgroup sequence, Phalaenopsis aphrodite, mapped on to the plastid phylogeny.

The letter codes designate loops as per Table 2. Main Figure: Phylogeny estimated using down-weighted loops (from the main panel, Fig. 1). Where equally parsimonious interpretations were possible, accelerated transformation has been used. (A) Part of the phylogeny estimated using entire loops for the foliosa/concreta group. The mapping of gains of two loop inversions shared by foliosal and foliosa2 on this topology is in constrast to the mapping on the topology using down-weighted loops (main figure). (B) A diagramatic representation of the stem-loop structure with the majority form of the loop sequence (in black). (C) The stem-loop structure with the proposed inversion of the loop sequence (in red).

(D) The consequence on the alignment before down-weighting of the loop sequence (loop seqeunce in bold - majority form; loop sequence with back colours - inverted form).

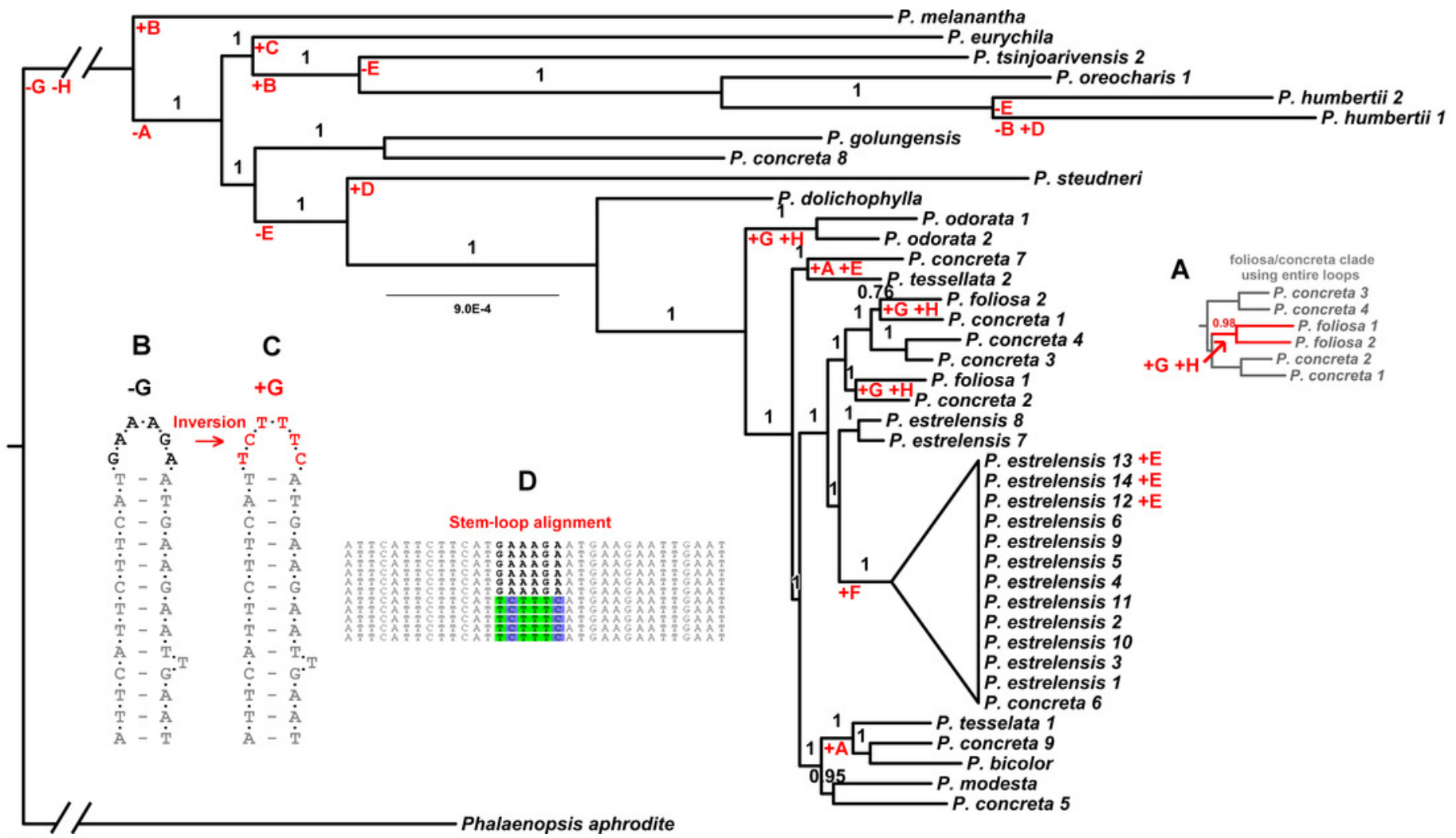




\section{Table $\mathbf{1}$ (on next page)}

Species and sample information of the accessions used in the study.

Species analysed; location of the collection and voucher; DNA concentration and purity before and after genomic library assembly. 
Table 1: Species and sample information of the accessions used in the study. Species analysed; location of the collection and voucher; DNA concentration and purity before and after genomic library assembly.

\begin{tabular}{|c|c|c|c|c|c|c|c|c|}
\hline \multirow{2}{*}{ SPECIES } & \multirow{2}{*}{ LOCATION } & \multirow{2}{*}{ VOUCHER } & \multirow{2}{*}{$\begin{array}{l}\text { ENA } \\
\text { REFERENCE }\end{array}$} & \multicolumn{3}{|c|}{$\begin{array}{c}\text { BEFORE GENOMIC LIBRARY } \\
\text { ASSEMBLY }\end{array}$} & \multicolumn{2}{|c|}{$\begin{array}{c}\text { AFTER GENOMIC } \\
\text { LIBRARY } \\
\text { ASSEMBLY } \\
\end{array}$} \\
\hline & & & & $\begin{array}{c}\text { Concentration } \\
(\mathrm{ng} / \mathrm{uL})\end{array}$ & $\begin{array}{l}\text { Purity } \\
260 / 280\end{array}$ & Volume & $\begin{array}{c}\text { Concentration } \\
(\mathrm{ng} / \mathrm{uL})\end{array}$ & $\begin{array}{l}\text { Purity } \\
\text { 260/280 }\end{array}$ \\
\hline P. bicolor $(=$ P.rosea $)$ & - & Kew 25884 & & 20.1 & 1.51 & 50 & 31.7 & 1.93 \\
\hline P. concreta (1) & Brazil, Distrito Federal & N.L.Abreu 254 & & 39.2 & 1.92 & 75 & 17.2 & 1.92 \\
\hline P. concreta (2) & Brazil, Distrito Federal & N.L.Abreu 254 & & 33.6 & 1.96 & 75 & 31.9 & 1.9 \\
\hline P. concreta (3) & Brazil, Bahia State & N.L.Abreu 251 & & 18 & 1.78 & 70 & 29.9 & 1.97 \\
\hline P. concreta (4) & Brazil, Bahia State & N.L.Abreu 251 & & 8.5 & 1.52 & 130 & 38.3 & 1.9 \\
\hline P. concreta (5) & Cameroon & A. Russell 40 (YA) & & 35 & 1.82 & 8 & 15 & 1.75 \\
\hline P. concreta (6) & Brazil & HBV ORCH 066004 & & 21.9 & 1.53 & 6 & 9.8 & 1.9 \\
\hline P. concreta (7) & Mauritius & HBV ORCH 07278 & & 26 & 1.78 & 13 & 32.4 & 1.85 \\
\hline P. concreta (8) & Réunion & HBV "Chase \& Samuel 1" & & 34 & 1.82 & 13 & 30 & 1.85 \\
\hline P. concreta (9) & Comoros & HBV ORCH 07417 & & 23.7 & 1.83 & 13 & 30.4 & 1.86 \\
\hline *P. concreta $(10)$ & Madagascar & Fischer\&Sieder FS3210 (WU) & & 21 & 1.81 & 13 & 9.4 & 1.63 \\
\hline *P. concreta (11) & Madagascar & Kew 17854 & & 70 & 1.65 & 67 & 9.6 & 1.6 \\
\hline *P. cornigera & Madagascar & Fischer\&Sieder FS3208 (WU) & & 22.2 & 1.76 & 11 & 7.7 & 1.58 \\
\hline P. dolichophylla & Cameroon & Kew 25886 & & 108.9 & 1.05 & 55 & 30.3 & 1.89 \\
\hline P. estrellensis (1) & Brazil, Minas Gerais State & N.L.Abreu 255 & & 29.8 & 1.81 & 65 & 33.7 & 1.9 \\
\hline P. estrellensis (2) & Brazil, Minas Gerais State & N.L.Abreu 255 & & 17.8 & 2.06 & 90 & 26 & 1.54 \\
\hline P. estrellensis (3) & Brazil, Minas Gerais State & N.L.Abreu 255 & & 11.9 & 1.82 & 75 & 35 & 1.86 \\
\hline P. estrellensis (4) & Brazil, Espirito Santo State & N.L.Abreu 253 & & 12.8 & 1.77 & 65 & 18.7 & 1.84 \\
\hline P. estrellensis (5) & Brazil, Espírito Santo State & N.L.Abreu 253 & & 22.4 & 1.87 & 70 & 21 & 1.96 \\
\hline P. estrellensis (6) & Brazil, Espírito Santo State & N.L.Abreu 253 & & 28.2 & 1.79 & 70 & 26.3 & 1.96 \\
\hline P. estrellensis (7) & Brazil, Bahia State & N.L.Abreu 252 & & 25.4 & 1.91 & 70 & 29.3 & 1.98 \\
\hline
\end{tabular}




\begin{tabular}{|c|c|c|c|c|c|c|c|}
\hline P. estrellensis (8) & Brazil, Bahia State & N.L.Abreu 252 & 14.6 & 1.79 & 70 & 22.4 & 2.02 \\
\hline P. estrellensis (9) & Brazil, Bahia State & N.L.Abreu 256 & 27.8 & 1.61 & 90 & 20.4 & 2.05 \\
\hline P. estrellensis (10) & Brazil, Bahia State & N.L.Abreu 256 & 23.8 & 1.81 & 75 & 23.1 & 1.93 \\
\hline P. estrellensis (11) & Brazil, Bahia State & N.L.Abreu 256 & 22.3 & 1.68 & 90 & 28 & 1.97 \\
\hline P. estrellensis (12) & Brazil, Trindade's Island & Nilber & 10.1 & 1.64 & 130 & 30 & 1.88 \\
\hline P. estrellensis (13) & Brazil, Trindade's Island & Nilber & 12.5 & 1.64 & 130 & 30 & 1.83 \\
\hline P. estrellensis (14) & Brazil, Trindade's Island & Nilber & 10.3 & 1.48 & 130 & 34.7 & 1.84 \\
\hline P. eurychila & Kenya & Kew 17963 & 207.6 & 0.94 & 85 & 13.7 & 1.98 \\
\hline P. foliosa (1) & Dominica & Kew 25887 & 14.7 & 1.58 & 56 & 31.8 & 1.96 \\
\hline P. foliosa (2) & Venezuela & HBV ORCH 07082 & 30.2 & 1.73 & 8 & 18.6 & 1.79 \\
\hline P. golungensis & Kenya & Kew 17966 & 104.7 & 1.14 & 115 & 26.1 & 1.88 \\
\hline *P. henrici & Madagascar & Kew 17856 & 22 & 1.52 & 56 & 7.7 & 2.04 \\
\hline P. humbertii (1) & Madagascar & Fischer\&Sieder FS2079 (WU) & 116.3 & 1.82 & 13 & 29.4 & 1.77 \\
\hline P. humbertii (2) & Madagascar & Fischer\&Sieder FS3017 (WU) & 35.1 & 1.93 & 11 & 34.2 & 1.89 \\
\hline P. melanantha & Kenya & Kew 17954 & 207.2 & 0.94 & 50 & 12.2 & 1.8 \\
\hline P. modesta & - & HBV ORCH 05165 & 56.8 & 1.35 & 13 & 31.7 & 1.93 \\
\hline P. odorata (1) & Nigeria & Kew 17857 & 33.7 & 1.56 & 58 & 46.8 & 1.8 \\
\hline P. odorata (2) & -Cameroon & A. Russell 42 (YA) & 36.9 & 1.91 & 13 & 26.2 & 1.91 \\
\hline P. oreocharis (1) & Madagascar & Fischer\&Sieder FS2082 (WU) & 58 & 1.74 & 13 & 30.2 & 1.87 \\
\hline$* P$. oreocharis (2) & Madagascar & Fischer\&Sieder FS3152 (WU) & 20.2 & 1.82 & 13 & 10.5 & 1.8 \\
\hline *P. paniculata (2) & Cameroon & L. Pearce 27 (YA) & 56.1 & 1.4 & 8 & 8.1 & 1.98 \\
\hline${ }^{*} P$. pinicola & Barzil & HBV ORCH 06606 & 31 & 1.11 & 7 & 9.2 & 1.98 \\
\hline P. steudneri & Kenya & Kew 17956 & 10.6 & 1.45 & 58 & 33.5 & 1.87 \\
\hline $\begin{array}{l}\text { P. tessellata (1) } \\
(=P \text {.concreta) }\end{array}$ & Madagascar & Kew 17859 & 176.2 & 1.1 & 58 & 32.7 & 1.89 \\
\hline $\begin{array}{l}\text { P. tessellata (2) } \\
(=P \text {.concreta) }\end{array}$ & Madagascar & Kew 17860 & 216.1 & 1.1 & 49 & 33.3 & 1.93 \\
\hline *P. tsinjoarivensis (1) & Madagascar & Fischer\&Sieder FS3209 (WU) & 19.3 & 1.83 & 13 & 9.3 & 1.79 \\
\hline P. tsinjoarivensis (2) & Madagascar & HBV FS4182 & 22.2 & 1.75 & 13 & 17.2 & 1.64 \\
\hline
\end{tabular}




\section{PeerJ}

$4 \quad$ *Species excluded due to low quality sequencing. 


\section{Table 2 (on next page)}

Alignment co-ordinates and sequences of putative stem-loop structures that appear to have undergone inversion in Polystachya.

The loops that appear to have undergone inversions are underlined. Bases in red would be treated as phylogenetically informative if the alignment doesn't take into account the inversion. Bases not involved in stem formation are in subscript. 

Polystachya. The loops that appear to have undergone inversions are underlined. Bases in red would be treated as phylogenetically informative if the alignment doesn't take into account the inversion. Bases not involved in stem formation are in subscript.

\begin{tabular}{|c|c|c|c|c|c|}
\hline Loop & $\begin{array}{l}\text { Alignment } \\
\text { co- } \\
\text { ordinates }\end{array}$ & Sequence (majority) & Sequence (minority) & $\begin{array}{l}\text { Substitutions } \\
\text { before/after } \\
\text { inversion } \\
\text { reverted } \\
\end{array}$ & Sequences (minority) \\
\hline $\mathrm{A}$ & $\begin{array}{l}74,660- \\
74,678\end{array}$ & $\begin{array}{l}\text { TCTATCTA-GAA- } \\
\text { TAGATAGA }\end{array}$ & $\begin{array}{l}\text { TCTATCTA-TTC- } \\
\text { TAGATAGA }\end{array}$ & $3 / 0$ & $\begin{array}{l}\text { bicolor, concreta7, concreta9, tesselata1, } \\
\text { melanantha, Phalaenopsis }\end{array}$ \\
\hline $\mathrm{B}$ & $\begin{array}{l}88,106- \\
88,142\end{array}$ & $\begin{array}{l}\text { GGCCCAATCTTT }_{C^{-}} \\
\text {TTTTTTTGAGGA- } \\
\text { AAAGATTGGGCC } \\
\end{array}$ & $\begin{array}{l}\text { GGCCCAATCTTT }_{\mathrm{C}^{-}} \\
\text {TCCTCAAAAAAA- } \\
\text { AAAGATTGGGCC } \\
\end{array}$ & $8 / 0$ & $\begin{array}{l}\text { humbertii2, oreocharis } 1 \text {, } \\
\text { tsinjoarivensis } 2, \text { melanantha }\end{array}$ \\
\hline $\mathrm{C}$ & $\begin{array}{l}90,456- \\
90,496\end{array}$ & $\begin{array}{l}\text { AGTAAGAACTCAGCG- } \\
\text { GGGTAAGGCCT- } \\
\text { CGCTGAGTTCTTACT }\end{array}$ & $\begin{array}{l}\text { AGTAAGAACTCAGCG- } \\
\text { AGGCCTTACCC- } \\
\text { CGCTGAGTTCTTACT* }\end{array}$ & $7 / 0$ & eurychila \\
\hline $\mathrm{D}$ & $\begin{array}{l}94,175- \\
94,222\end{array}$ & $\begin{array}{l}\text { ATTGAAGTAATGAGCCC- } \\
\text { CAAGATGAATATGA- } \\
\text { GGGCTCATTACTTCAAT }\end{array}$ & $\begin{array}{l}\text { ATTGAAGTAATGAGCCC- } \\
\text { TCATATTCATCTTG- } \\
\text { GGGCTCATTACTTCAAT }\end{array}$ & $8 / 0$ & humbertiil, steudneri \\
\hline $\mathrm{E}$ & $\begin{array}{l}94,679- \\
94,717\end{array}$ & $\begin{array}{l}\text { GTATCTAAGGAAGATCC- } \\
\text { AAAGG- } \\
\text { GGATCTTCCTTAGATAC }\end{array}$ & $\begin{array}{l}\text { GTATCTAAGGAAGATCC- } \\
\text { CTTCT- } \\
\text { GGATCTTCCTTAGATAC }\end{array}$ & $5 / 2$ & $\begin{array}{l}\text { estrelensis12, estrelensis } 13 \text {, } \\
\text { estrelensis14, eurychila, concreta7, } \\
\text { concreta8, golungensis, oreocharis1, } \\
\text { melanantha, humbertii1, Phalaenopsis }\end{array}$ \\
\hline $\mathrm{F}$ & $\begin{array}{l}97,230- \\
97,258\end{array}$ & $\begin{array}{l}\text { AACGTCCAGTG-CCAAAGT- } \\
\text { CACTGAATGGG }\end{array}$ & $\begin{array}{l}\text { ^CCCATTCAGTG-ACTTTGG- } \\
\text { CACTGAATGGG }\end{array}$ & $6 / 0$ & $\begin{array}{l}\text { All } 13 \text { sequences of the estrelensis clade } \\
\text { (cartooned in Figs. } 2 \text { and } 4 \text { ) }\end{array}$ \\
\hline $\mathrm{G}$ & $\begin{array}{l}104,698- \\
104,730\end{array}$ & $\begin{array}{l}\text { ATTC }_{\text {A ATTCTTC- }} \\
\text { ATTCTTTCAA- } \\
\text { GAAGAATGAAT }\end{array}$ & $\begin{array}{l}\text { ATTC }_{\text {A ATCTTC- }} \\
\text { ATGAAAGAAA- } \\
\text { GAAGAATGAAT }\end{array}$ & $6 / 0$ & $\begin{array}{l}\text { foliosa1, foliosa2, odorata1, odorata2, } \\
\text { Phalaenopsis }\end{array}$ \\
\hline $\mathrm{H}$ & $\begin{array}{l}106,618- \\
106,650\end{array}$ & $\begin{array}{l}\text { ATTCATTCTTCAT- } \\
\text { GAAAGA- } \\
\text { ATGAAGAAT }_{\mathrm{T}} \text { GAAT }\end{array}$ & $\begin{array}{l}\text { ATTCATTCTTCAT-TCTTTC- } \\
\text { ATGAAGAAT }_{\mathrm{T}} \text { GAAT }\end{array}$ & $6 / 0$ & $\begin{array}{l}\text { foliosa1, foliosa2, odorata1, odorata2, } \\
\text { Phalaenopsis }\end{array}$ \\
\hline
\end{tabular}

*Occurs in only one sequence. ${ }^{\wedge}$ Only the sequences with the inversion appear to form the stem in this case. 